\section{(2) OPEN ACCESS}

\title{
Hospitalised patients with palliative care needs: Spain and Sweden compared
}

\section{Anna Sandgren (D) , ${ }^{1}$ Francisco P García-Fernández (i) , 2 Daniel Gutiérrez Sánchez (D) , 3,4 Peter Strang (D) , 5,6 Isabel M López-Medina (i) ${ }^{2}$}

\begin{abstract}
${ }^{1}$ Center for Collaborative Palliative Care, Department of Health and Caring Sciences, Linnaeus University, Växjö, Sweden

${ }^{2}$ Nursing Department, University of Jaén, Jaen, Spain ${ }^{3}$ Nursing and Podiatry, University of Malaga, Malaga, Spain ${ }^{4}$ Biomedical Research Institute of Málaga, Málaga, Spain ${ }^{5}$ Oncology-Pathology, Karolinska Institute, Stockholm, Sweden ${ }^{6}$ Stockholms Sjukhem Forskning utbildning och utveckling, Stockholm, Sweden
\end{abstract}

\section{Correspondence to}

Dr Anna Sandgren, Center for Collaborative Palliative Care, Department of Health and Caring Sciences, Linnaeus University, SE35195 Växjö, Sweden; anna.sandgren@|nu.se

Received 7 May 2020 Revised 23 November 2020 Accepted 26 November 2020

\section{Check for updates}

(c) Author(s) (or their employer(s)) 2020. Re-use permitted under CC BY-NC. No commercial re-use. See rights and permissions. Published by BMJ.

\begin{tabular}{|l|}
\hline To cite: Sandgren A, \\
García-Fernández FP, \\
Gutiérrez Sánchez D, \\
et al. BMJ Supportive \& \\
Palliative Care Epub ahead \\
of print: [please include Day \\
Month Year]. doi:10.1136/ \\
bmjspcare-2020-002417
\end{tabular}

\section{ABSTRACT}

Objectives This study aimed to describe and compare symptoms, care needs and types of diagnoses in hospitalised patients with palliative care needs in Spain and Sweden.

Methods A cross-sectional, population-based study was carried out at two hospitals in both Spain and Sweden. Using a questionnaire, we performed 154 one-day inventories $(n=4213)$ in Spain and 139 in Sweden $(n=3356)$ to register symptoms, care needs and diagnoses. Descriptive analyses were used.

Results The proportion of patients with care needs in the two countries differed (Spain $7.7 \%$ vs Sweden $12.4 \%, p<0.001$ ); however, the percentage of patients with cancer and non-cancer patients was similar. The most prevalent symptoms in cancer and non-cancer patients in both countries were deterioration, pain, fatigue and infection. The most common cancer diagnosis in both countries was lung cancer, although it was more common in Spain $(p<0.01)$, whereas prostate cancer was more common among Swedish men $(p<0.001)$. Congestive heart failure $(p<0.001)$ was a predominant noncancer diagnosis in Sweden, whereas in Spain, the most frequent diagnosis was dementia $(p<0.001)$. Chronic obstructive pulmonary disease was common in both countries, although its frequency was higher in Spain $(p<0.05)$. In total, patients with cancer had higher frequencies of pain $(p<0.001)$ and nausea $(p<0.001)$, whereas non-cancer patients had higher frequencies of deterioration $(p<0.001)$ and infections $(p<0.01)$.

Conclusions The similarities in symptoms among the patients indicate that the main focus in care should be on patient care needs rather than diagnoses. Integrating palliative care in hospitals and increasing healthcare professional competency can result in providing optimal palliative care.

\section{BACKGROUND}

Several factors determine the place of care in the of end of life, such as characteristics of community-based care, presence of informal caregivers, illness factors, overall health and complexity of care needs. ${ }^{1}$ Moreover, if a diagnostic procedure is a prerequisite for a care intervention, this may also affect place of care. Many patients receive palliative care in an institution despite a wish to stay home. ${ }^{2}$ Gomes et $\mathrm{al}^{3}$ found that most people prefer the home environment even if their illness progresses. However, this is not always a realistic option and hospital care remains an alternative.

Despite efforts to offer palliative care in primary care and at nursing homes, admissions to acute hospitals still occur. Therefore, a considerable proportion of patients are cared for and die in acute hospital environments. $^{45}$ A high percentage of palliative care patients continue to be cared for in hospitals, which theoretically are designed for curative and lifeprolonging measures, not primarily for palliative care. Vogl et $a l^{6}$ also argue that patients with palliative care needs differ from acute patients regarding the care they need, as does the complexity of their unique situation.

Earlier research focused on symptoms and care needs in patients with cancer in the context of specialised palliative care at hospice and palliative care units ${ }^{7-10}$ and focused less on acute care hospitals and reasons for hospitalisation. ${ }^{11-13}$ More knowledge is needed regarding the extent of palliative care needs and prevalence and characteristics of symptoms in acute care hospitals, especially in regions with limited availability to specialised palliative care 24/7. Moens et $a l^{14}$ argue that research is also needed to compare 
palliative care and associated problems between patients with cancer and non-cancer patients using the same measuring tools.

It is important to determine the symptoms and care needs of patients and assess whether the needs differ across various types of patients and sociocultural contexts in different countries. The unique aim of this study was, therefore, to describe and compare symptoms, care needs and types of diagnoses among hospitalised palliative patients in Spain and Sweden.

\section{METHODS}

\section{Design and setting}

This cross-sectional, population-based study was conducted at the departments of Oncology, Surgery and Medicine in two Spanish and two Swedish hospitals. Those in Spain served almost 200000 individuals on all levels, and served as specialised hospitals (tertiary care hospitals) for 650000 inhabitants. The two hospitals in Sweden served almost 194000 individuals, in a medium-sized county in southern Sweden. The counties in Spain and Sweden had no 24 hours specialised palliative care services but had access to a palliative advisory team during daytime hours, from Monday to Friday. These teams affiliated with the hospitals and supported healthcare professionals in the home healthcare. In Spain, the advisory team consisted of 3 physicians, 13 registered nurses and 13 nurses assistants. In Sweden, the team consisted of 3 physicians (halftime), 6 nurses and one social worker. In one of the internal medicine wards in Spain, 10 beds were reserved mainly for patients with palliative care needs. The counties in Sweden had no such reserved beds.

\section{Questionnaire}

A questionnaire with 14 items was used. The questionnaire included organisational and healthcare aspects (clinic wards, number of beds, number of palliative patients, etc), demographic data (age, sex, main diagnosis, etc), and a list of a total 21 different symptoms and/or interventions during the hospitalisation. An optional comments section was provided. The detailed WHO's definition of palliative care was printed on the back of the questionnaire and used as an aid for the identification of patients as being in a palliative phase. WHO defines palliative care ${ }^{15}$ as an approach 'that improves the quality of life of patients and their families facing the problem associated with life-threatening illness'. The comprehensive and detailed definition also underlines (among other issues) the importance of '...early identification and impeccable assessment and treatment of pain and other problems, physical, psychosocial and spiritual'. The questionnaire was pilot tested in 2002 for face and content validity by a panel of palliative care experts ${ }^{16}$ and has been used in earlier studies. ${ }^{1316}$

\section{Data collection}

On a specific day every month, the nurses in cooperation with the physicians, assessed all inpatients regardless of their primary reasons for admission, and those who were assessed as palliative were registered in the questionnaires. In order to get comparable assessments, it was of utmost importance that each nurse knew how to assess patients as palliative and how to complete the questionnaire. We therefore met with the nurses in charge of the different wards to discuss how to assess a patient as being in a palliative phase in accordance with the WHO's definition of palliative care. ${ }^{15}$ A patient whose disease was not responsive to curative treatment and where the prognosis was limited, was defined as a patient being in a palliative phase. The patient could be in either an early or a late palliative phase. To get comparable assessments of how to identify right patients, we discussed the palliative care definition and how to perform assessments by discussing different patient cases. We also explained that the reasons for hospitalisation could be different symptoms (such as pain and nausea) and/or interventions (such as diagnostic procedure and palliative radiotherapy).

In Spain, data were collected in 16 wards in 2015: 1 oncology ward ( 22 beds), 4 surgical wards (127 beds) and 11 medical wards (296 beds). In Sweden data were collected in 12 wards in 2012: 1 oncology ward (17 beds), 4 surgical wards ( 85 beds) and 7 medical wards (162 beds). In Spain, there were 154 one-day inventories (data missing for 5 days, ie, 3.1\%) and in Sweden, there were 139 one-day inventories (data missing for 5 days, ie, 3.5\%). In both Spain and Sweden, all inpatients on the involved wards were assessed once a month during 1 year. In total, 4213 patients were assessed in Spain and 3356 patients in Sweden.

\section{Statistical analysis}

A descriptive analysis of demographic and clinical variables was performed. Qualitative variables are presented as frequency and percentages. In the quantitative variables, the mean, median and SD were calculated. The variables were compared using bivariate analyses. Pearson's $\chi^{2}$ test test was used for comparison of proportions, and Mann-Whitney U test was used after applying the Kolgomorov-Smirnov normality test. Values of $\mathrm{p}<0.05$ were considered statistically significant. IBM SPSS statistics V.24 (IBM) was used to perform the analyses.

\section{RESULTS}

Regarding hospitalised patients with palliative care needs, there was a significant difference between Spain (325/4213) and Sweden (354/3356), with 7.7\% and $12.4 \%$, respectively $(\mathrm{p}<0.001)$. Of those, $76.6 \%$ and $74.6 \%$ of the Spanish and Swedish patients had cancer diagnoses (data not shown). The patients were significantly younger in Spain $(p<0.001)$ and more than half 
Table 1 Characteristics, situational data and prevalence of symptoms and care needs for all palliative patients

\begin{tabular}{|c|c|c|c|c|c|c|}
\hline & \multicolumn{3}{|l|}{ Spain } & \multicolumn{3}{|l|}{ Sweden } \\
\hline & All $(n=325)$ & Male $(n=201)$ & Female $(n=124)$ & All $(n=354)$ & Male $(n=181)$ & Female $(n=173)$ \\
\hline Age; mean, (range) SD & $\begin{array}{l}\text { 68.6, }(21-101) \\
14.4\end{array}$ & $\begin{array}{l}69.9,(21-94) \\
12.8\end{array}$ & $66.8,(21-94) 16.6$ & $\begin{array}{l}74.9,(38-102) \\
12.2^{\star * *}\end{array}$ & $\begin{array}{l}75.6,(38-98) \\
11.5^{\star * *}\end{array}$ & $\begin{array}{l}74.2,(45-102) \\
12.8^{* * *}\end{array}$ \\
\hline Connected to palliative team; \% & $52^{* * *}$ & $52.7^{* * *}$ & $50.8^{* * *}$ & 17.5 & 16.6 & 18.5 \\
\hline $\begin{array}{l}\text { No of symptoms and care needs per } \\
\text { patient; mean, median (range) }\end{array}$ & $3.0,3(1-8)$ & $3.0,3(1-8)$ & $3.1,3(1-6)$ & $2.8,3(1-9)$ & $2.8,3(1-8)$ & $2.9,3(1-9)$ \\
\hline \multicolumn{7}{|l|}{ Symptoms/care needs; \% } \\
\hline Blood transfusion & 6.5 & 7.0 & 5.6 & 10.5 & 11.0 & 9.8 \\
\hline Congestive heart failure treatment & 4.0 & 3.5 & 4.8 & $11.0^{* *}$ & $9.9^{*}$ & $12.1^{*}$ \\
\hline Deterioration & $68.6^{* * *}$ & $67.7^{* * *}$ & $70.2^{* * *}$ & 42.4 & 38.1 & 46.8 \\
\hline Diagnostic procedure & 11.7 & 13.4 & 8.9 & $18.4^{*}$ & 16.6 & $20.2^{* *}$ \\
\hline Fatigue & 24.6 & 22.4 & 28.2 & 28.0 & 28.7 & 27.2 \\
\hline Infection & 20.3 & 18.4 & 23.4 & 26.0 & $29.8^{* *}$ & 22.0 \\
\hline Infusion & $11.1^{*}$ & 8.0 & $16.1^{* *}$ & 6.8 & 7.2 & 6.4 \\
\hline Nausea & 17.5 & 14.9 & 21.8 & 12.7 & 10.5 & 15.0 \\
\hline Nutrition & 18.2 & 18.4 & 17.7 & 20.3 & 19.3 & 21.4 \\
\hline Obstipation & $11.7^{* *}$ & 10.9 & $12.9^{*}$ & 5.6 & 6.1 & 5.2 \\
\hline Pain & $45.5^{*}$ & 44.8 & $46.8^{*}$ & 35.9 & 37.0 & 34.7 \\
\hline Pleuracentes & 1.8 & 1.5 & 2.4 & $5.1^{*}$ & $5.5^{*}$ & 4.6 \\
\hline Palliative radiotherapy & 0.9 & - & 2.4 & $12.7^{* * *}$ & $13.3^{* * *}$ & $12.1^{* *}$ \\
\hline Psychosocial issues & $9.2^{* * *}$ & $9.0^{*}$ & $9.7^{* * *}$ & 1.7 & 2.8 & 0.6 \\
\hline Social problems & $14.8^{* * *}$ & $16.4^{* *}$ & 12.1 & 6.5 & 6.1 & 6.9 \\
\hline Palliative surgery & 5.8 & 6.0 & 5.6 & 8.5 & 8.8 & 8.1 \\
\hline
\end{tabular}

Significant difference between the countries (indicated with * ${ }^{*}$ at the higher value).

${ }^{*} \mathrm{P}<0.05,{ }^{* *} p<0.01,{ }^{* *} p<0.001$.

\begin{tabular}{|c|c|c|c|c|c|c|}
\hline & \multicolumn{3}{|l|}{ Spain } & \multicolumn{3}{|l|}{ Sweden } \\
\hline & All $(n=76)$ & Male $(n=39)$ & Female $(n=37)$ & All $(n=90)$ & Male $(n=46)$ & Female $(n=44)$ \\
\hline Age; mean, (range) SD & $78.5,(21-101) 11.8$ & $\begin{array}{l}\text { 79.8, (40-101) } \\
10.1\end{array}$ & $\begin{array}{l}77.1,(21-94) \\
13.4\end{array}$ & $\begin{array}{l}84.7,(56-102) \\
8.4^{* \star *}\end{array}$ & $\begin{array}{l}85.1,(56-96) \\
7.8^{* *}\end{array}$ & $\begin{array}{l}84.3,(66-102) \\
9.0^{* *}\end{array}$ \\
\hline $\begin{array}{l}\text { No of symptoms and care needs per } \\
\text { patient; mean, median (range) }\end{array}$ & $3.3,3(1-7)^{* * *}$ & $3.5,3(1-7)^{\star *}$ & $3.2,3(1-6)^{*}$ & $2.4,2(1-6)$ & $2.3,2(1-5)$ & $2.6,2(1-6)$ \\
\hline Connected to palliative team; \% & $18.4^{\star *}$ & $20.5^{* *}$ & $16.2^{\star *}$ & 3.3 & 4.3 & 2.3 \\
\hline \multicolumn{7}{|l|}{ Symptoms/care needs; \% } \\
\hline Blood transfusion & 6.6 & 7.7 & 5.4 & 5.6 & 2.2 & 9.1 \\
\hline Congestive heart failure treatment & 9.2 & 10.3 & 8.1 & $34.4^{* * *}$ & $32.6^{*}$ & $36.4^{* *}$ \\
\hline Diagnostic procedure & 13.2 & 10.3 & 16.2 & 12.2 & 8.7 & 15.9 \\
\hline Deterioration & $90.8^{* * *}$ & $87.2^{* * *}$ & $94.6^{* * *}$ & 48.9 & 41.3 & 56.8 \\
\hline Fatigue & 32.9 & 28.2 & $37.8^{*}$ & 21.1 & 23.9 & 18.2 \\
\hline Infection & 31.6 & 33.3 & 29.7 & 34.4 & 39.1 & 29.5 \\
\hline Inhalation & 5.3 & 10.3 & - & 10.0 & 10.9 & 9.1 \\
\hline Infusion & $18.4^{* *}$ & 10.3 & $27.0^{* *}$ & 3.3 & 4.3 & 2.3 \\
\hline Nausea & $9.2^{*}$ & 12.8 & 5.4 & 1.1 & 2.2 & - \\
\hline Nutrition & 26.3 & $25.6^{*}$ & 27.0 & 18.9 & 8.7 & 29.5 \\
\hline Obstipation & $9.2^{*}$ & 12.8 & 5.4 & 1.1 & 2.2 & - \\
\hline Pain & 30.3 & 35.9 & 24.3 & 22.2 & 23.9 & 20.5 \\
\hline Psychosocial issues & $11.8^{* *}$ & 10.3 & $13.5^{*}$ & 1.1 & 2.2 & - \\
\hline Social problems & $17.1^{* * *}$ & $25.6 * * *$ & 8.1 & 1.1 & - & 2.3 \\
\hline
\end{tabular}

Significant difference between the countries (indicated with * at the higher value).

${ }^{*} \mathrm{P}<0.05,{ }^{* *} \mathrm{p}<0.01,{ }^{* *} \mathrm{p}<0.001$. 
Table 3 Characteristics, situational data and prevalence of symptoms and care needs for patients with cancer

\begin{tabular}{|c|c|c|c|c|c|c|}
\hline & \multicolumn{3}{|l|}{ Spain } & \multicolumn{3}{|l|}{ Sweden } \\
\hline & All $(n=249)$ & Male $(n=162)$ & Female $(n=87)$ & All $(n=264)$ & Male $(n=135)$ & Female $(n=129)$ \\
\hline Age; mean, (range) SD & $\begin{array}{l}65.6,(28-92) \\
13.7\end{array}$ & $\begin{array}{l}67.4,(32-92) \\
12.2\end{array}$ & $\begin{array}{l}62.3,(28-91) \\
15.8\end{array}$ & $\begin{array}{l}71.5,(38-98) \\
11.4^{\star \star *}\end{array}$ & $\begin{array}{l}72.3,(38-98) \\
10.8^{\star * *}\end{array}$ & $\begin{array}{l}70.7,(45-94) \\
12.1^{* \star *}\end{array}$ \\
\hline $\begin{array}{l}\text { No of symptoms and care needs per } \\
\text { patient; mean, median (range) }\end{array}$ & $2.9,3(1-8)$ & $2.8,3(1-8)$ & $3.1,3(1-6)$ & $3.0,3(1-9)$ & $3.0,3(1-8)$ & $3.0,3(1-9)$ \\
\hline Connected to palliative team; $\%$ & $62.2^{* * *}$ & $60.5^{* * *}$ & $65.5^{* * *}$ & 22.3 & 20.7 & 24 \\
\hline \multicolumn{7}{|l|}{ Symptoms/care needs; $\%$} \\
\hline Abdominal surgery & 4.0 & 3.7 & 4.6 & 5.3 & 6.7 & 3.9 \\
\hline Blood transfusion & 6.4 & 6.8 & 5.7 & $12.1^{*}$ & $14.1^{*}$ & 10.1 \\
\hline Diagnostic procedure & 11.4 & 14.2 & 5.7 & $20.5^{* *}$ & 19.3 & $21.7^{\star *}$ \\
\hline Deterioration & $61.8^{* * *}$ & $63.0^{* * *}$ & $59.8^{*}$ & 40.2 & 37.0 & 43.4 \\
\hline Fatigue & 22.1 & 21.0 & 24.1 & $30.3^{*}$ & 30.4 & 30.2 \\
\hline Infection & 16.9 & 14.8 & 20.7 & 23.1 & $26.7^{*}$ & 19.4 \\
\hline Infusion & 8.8 & 7.4 & 11.5 & 8.0 & 8.1 & 7.8 \\
\hline Nausea & 20.1 & 15.4 & 28.7 & 16.7 & 13.3 & 20.2 \\
\hline Nutrition & 15.7 & 16.7 & 13.8 & 20.8 & 23.0 & 18.6 \\
\hline Obstipation & $12.4^{*}$ & 10.5 & $16.1^{*}$ & 7.2 & 7.4 & 7.0 \\
\hline Pain & $50.2^{*}$ & 46.9 & $56.3^{*}$ & 40.5 & 41.5 & 39.5 \\
\hline Pleuracentes & 1.6 & 0.6 & 3.4 & $6.4^{* *}$ & $6.7^{* *}$ & 6.2 \\
\hline Palliative radiotherapy & 1.2 & - & 3.4 & $17.0^{* * *}$ & $17.8^{* * *}$ & $16.3^{* *}$ \\
\hline Psychosocial issues & $8.4^{* *}$ & $8.6^{*}$ & $8.0^{* *}$ & 1.9 & 3.0 & 0.8 \\
\hline Social problems & $14.1^{*}$ & 14.2 & 13.8 & 8.3 & 8.1 & 8.5 \\
\hline Palliative surgery & 7.6 & 7.4 & 8.0 & 9.8 & 10.4 & 9.3 \\
\hline
\end{tabular}

Significant difference between the countries (indicated with ${ }^{*}$ at the higher value).

${ }^{*} P<0.05,{ }^{* *} p<0.01,{ }^{* *} p<0.001$.

of the patients in Spain were enrolled in a palliative care team $(\mathrm{p}<0.001)$ (table 1$)$.

\section{Symptoms and care needs}

The number of symptoms and care needs per patient for the whole study group was similar in Spain (3.0) and Sweden (2.8) (table 1), whereas Spanish noncancer patients had more symptoms and care needs, 3.3 compared with $2.4(\mathrm{p}<0.001)$ (table 2$)$.

The most prevalent symptoms causing hospitalisation in each country were deterioration, pain, fatigue and infection (table 1). However, the frequencies varied; deterioration $(p<0.001)$, pain $(p<0.05)$, obstipation $(\mathrm{p}<0.01)$ were higher in Spain. In a subanalysis of patients with cancer (table 3), pain was a more frequent reason for hospitalisation in Spanish patients $(50.2 \%$ vs $40.5 \%, \mathrm{p}<0.05)$, whereas fatigue was less frequent $(22.1 \%$ vs $30.3 \%, \mathrm{p}<0.05)$. In non-cancer patients, deterioration was much more common $(90.8 \%$ vs $48.9 \%, \mathrm{p}<0.001)$. Furthermore, nausea and obstipation were more frequent problems among Spanish non-cancer patients $(<0.05$ and $<0.05$, respectively) (table 2). The differences between male and female patients within each country were minor.

Hospitalisation due to social problems $(\mathrm{p}<0.001)$, psychosocial issues $(p<0.001)$ and need of infusions $(p<0.05)$ were more prevalent in Spanish patients, whereas the need for palliative radiotherapy $(p<0.001)$, congestive heart failure treatment $(p<0.01)$ or diagnostic procedures $(p<0.05)$ were more frequent in Sweden (table 1).

In Spanish patients with cancer, psychosocial issues and social problems were significantly more common reasons for hospitalisation, whereas interventions such as palliative radiotherapy, pleuracenteses, diagnostic procedures and blood transfusions were more prevalent in the Swedish settings $(\mathrm{p}<0.05-\mathrm{p}<0.001)$ (table 3).

Among non-cancer patients, psychosocial issues and social problems were more frequent reasons for admission in Spain than in Sweden. This was also true for the need of infusions, whereas congestive heart failure treatment was the most prevalent cause in all noncancer patients in Sweden, and much more common than in Spain $(34.4 \%$ vs 9.2\%, $\mathrm{p}<0.001)$. Details are presented in table 2.

\section{All patients with cancer versus all non-cancer patients}

When comparing all patients with cancer $(n=513)$ to all non-cancer patients $(n=166)$ regardless of country, patients with cancer had higher frequencies of pain $(\mathrm{p}<0.001)$, nausea $(\mathrm{p}<0.001)$ and obstipation $(\mathrm{p}<0.05)$. However, non-cancer patients had higher frequencies of deterioration $(\mathrm{p}<0.001)$ and infections $(\mathrm{p}<0.01)$ (table 4).

Diagnoses in hospitalised palliative patients with cancer In hospitalised palliative patients with palliative cancer, lung cancer was the most frequent cancer in both 
Table 4 Prevalence of symptoms and care needs for all hospitalised cancer versus non-cancer palliative patients

\begin{tabular}{|c|c|c|c|c|c|c|}
\hline & \multicolumn{3}{|c|}{ Patients with cancer } & \multicolumn{3}{|c|}{ Non-cancer patients } \\
\hline & All $(n=513)$ & Male $(n=297)$ & Female $(n=216)$ & All $(n=166)$ & Male $(n=85)$ & Female $(n=81)$ \\
\hline $\begin{array}{l}\text { No of symptoms and care needs per } \\
\text { patient; mean, median (range) }\end{array}$ & $3.0,3(1-9)$ & $2.9,3(1-8)$ & $3.0,3(1-9)$ & $2.7,3(1-7)$ & $2.8,3(1-7)$ & $2.9,3(1-6)$ \\
\hline \multicolumn{7}{|l|}{ Symptoms/care needs; \% } \\
\hline Deterioration & 51.1 & 51.9 & 50 & $68.1^{* * *}$ & 62.4 & $74.1^{* * *}$ \\
\hline Diagnostic procedure & 16 & 16.5 & 15.3 & 12.7 & 9.4 & 16 \\
\hline Fatigue & 26.5 & 25.6 & 27.8 & 26.5 & 25.9 & 27.2 \\
\hline Infection & 20.1 & 20.2 & 19.9 & $33.1^{* *}$ & $36.5^{* *}$ & 29.6 \\
\hline Nausea & $18.3^{* * *}$ & 14.5 & $23.6^{* * *}$ & 4.8 & 7.1 & 2.5 \\
\hline Nutrition & 18.3 & 19.5 & 16.7 & 22.3 & 16.5 & $28.4^{*}$ \\
\hline Obstipation & $9.7^{*}$ & 9.1 & $10.6^{*}$ & 4.8 & 7.1 & 2.5 \\
\hline Pain & $45.6^{* * *}$ & $45.1^{*}$ & $46.3^{* * *}$ & 25.9 & 29.4 & 22.2 \\
\hline Social problems & 11.1 & 11.4 & 10.6 & 8.4 & 11.8 & 4.9 \\
\hline
\end{tabular}

Significant difference between patients with cancer and non-cancer patients (indicated with * at the higher value).

${ }^{*} \mathrm{P}<0.05,{ }^{*} \mathrm{p}<0.01,{ }^{* *} \mathrm{p}<0.001$.

countries, although prevalence was lower in Sweden $(\mathrm{p}<0.01)$. In contrast, prostate cancer among men was significantly higher in Sweden $(\mathrm{p}<0.001)$. In women, the most prevalent cancer in both Spain and Sweden was gynaecological (NS) (table 5).

\section{Diagnoses in hospitalised palliative non-cancer patients}

The diagnoses of non-cancer palliative patients varied significantly between the countries. In Spain, dementia was the most frequent diagnosis and more common than in Sweden $(\mathrm{p}<0.001)$. Chronic obstructive pulmonary disease was common in both countries, although higher in Spain $(\mathrm{p}<0.05)$. Congestive heart failure was the most frequent diagnosis in Sweden and more common than in Spain $(\mathrm{p}<0.001)$. Parkinson's, liver failure and haemorrhage diagnoses were found in Spanish patients, whereas there was minimal or no prevalence in Sweden (table 6).

\section{DISCUSSION}

In all healthcare systems, competent care is a goal. Generally, only symptoms or care needs that cannot be managed on other levels of care should be reasons for admission to an acute care hospital. Optimally developed primary care, and nursing homes with adequate resources should provide palliative care to patients. Our results reinforce this, indicating that $7.7 \%$ and $12.4 \%$ of the Spanish and Swedish patients at acute care hospitals were palliative patients for whom alternative care levels would have been desirable. These results are in line with the percentage of palliative patients found

Table 5 Prevalence of cancer diagnosis in hospitalised palliative patients in Spain and Sweden

\begin{tabular}{|c|c|c|c|c|c|c|}
\hline & \multicolumn{3}{|l|}{ Spain } & \multicolumn{3}{|l|}{ Sweden } \\
\hline & All $(n=249)$ & Male (n=162) & Female $(n=87)$ & All $(n=264)$ & Male $(n=135)$ & Female $(n=129)$ \\
\hline \multicolumn{7}{|l|}{ Cancer diagnosis; \% } \\
\hline Bile duct & 2.4 & 1.9 & 3.4 & 4.2 & 2.2 & 6.2 \\
\hline Breast & 3.6 & - & 10.3 & 7.6 & - & 15.5 \\
\hline Cerebral & 3.2 & 1.9 & 5.7 & 2.7 & 2.2 & 3.1 \\
\hline Colorectal & 13.3 & 13.6 & 12.6 & 11.4 & 11.1 & 11.6 \\
\hline Gynaecological & 4.8 & - & 13.8 & 8.7 & - & 17.8 \\
\hline Lung & $21.7^{*}$ & $29.0 * * *$ & 8.0 & 11.4 & 10.4 & 12.4 \\
\hline Lymphoma & 2.4 & 1.9 & 3.4 & 3.4 & 5.9 & 0.8 \\
\hline Melanoma & 1.6 & 1.2 & 2.3 & 3.0 & 0.7 & 5.4 \\
\hline Pancreas & 11.2 & 11.1 & 11.5 & 7.6 & 8.9 & 6.2 \\
\hline Prostate & 3.6 & 5.6 & - & $11.4^{* *}$ & $22.2^{* * *}$ & - \\
\hline Stomach/oesophagus & 12.0 & 12.3 & 11.5 & 8.7 & 11.1 & 6.2 \\
\hline Unknown primary & 2.0 & 3.1 & - & 4.9 & 5.2 & $4.7^{*}$ \\
\hline Urological & 6.0 & 6.8 & 4.6 & 3.8 & 6.7 & 0.8 \\
\hline
\end{tabular}

Significant difference between the countries (indicated with * at the higher value).

${ }^{*} \mathrm{P}<0.05,{ }^{* *} \mathrm{p}<0.01,{ }^{* * *} \mathrm{p}<0.001$. 
Table 6 Prevalence of diagnosis (non-cancer) in hospitalised palliative patients in Spain and Sweden

\begin{tabular}{|c|c|c|c|c|c|c|}
\hline & \multicolumn{3}{|l|}{ Spain } & \multicolumn{3}{|l|}{ Sweden } \\
\hline & All $(n=76)$ & Male $(n=39)$ & Female $(n=37)$ & All $(n=90)$ & Male $(n=46)$ & Female $(n=44)$ \\
\hline \multicolumn{7}{|l|}{ Diagnosis (non-cancer); \% } \\
\hline Acute myocardial infarction & 2.6 & 2.6 & 2.7 & 6.7 & 2.2 & 11.4 \\
\hline Chronic renal failure & 6.6 & 7.7 & 5.4 & 10.0 & 15.2 & 4.5 \\
\hline Circulatory insufficiency & $13.2^{*}$ & 12.8 & 13.5 & 4.4 & 6.5 & 2.3 \\
\hline Congestive heart failure & 3.9 & 2.6 & 5.4 & $37.8^{* * *}$ & $39.1^{* * *}$ & $36.4^{* *}$ \\
\hline Chronic obstructive pulmonary disease & $18.4^{*}$ & 23.1 & 13.5 & 7.8 & 8.7 & 6.8 \\
\hline Dementia & $26.3^{* * *}$ & $17.9^{*}$ & $35.1^{* * *}$ & 2.2 & 2.2 & 2.3 \\
\hline Haemorrhage & $5.3^{*}$ & 2.6 & 8.1 & - & - & - \\
\hline Intestinal inflammation & 2.6 & - & 5.4 & - & - & - \\
\hline Liver failure & 7.9 & $12.8^{*}$ & 2.7 & 2.2 & - & 4.5 \\
\hline Parkinson & $7.9^{*}$ & 7.7 & 8.1 & 1.1 & 2.2 & - \\
\hline Pneumonia & 1.3 & 2.6 & - & 4.4 & 6.5 & 2.3 \\
\hline Sclerosis & 3.9 & - & 8.1 & - & - & - \\
\hline Septicaemia & 3.9 & 2.6 & 5.4 & - & - & - \\
\hline Stroke & 14.5 & 15.4 & 13.5 & 14.4 & 17.4 & 11.4 \\
\hline
\end{tabular}

Significant difference between the countries (indicated with * at the higher value).

${ }^{*} \mathrm{P}<0.05,{ }^{* *} \mathrm{p}<0.01,{ }^{* *} \mathrm{p}<0.001$.

in hospitals in Germany (6.7\%), ${ }^{17}$ Belgium (9.4\%), ${ }^{18}$ and in a New Zealand hospital (19.8\%). ${ }^{19}$

Deterioration was the most frequent symptom in both countries, and for non-cancer patients the figures for Spain and Sweden were as high as $90.8 \%$ and $48.9 \%$, respectively. The mean age was high for this subpopulation. The prevalence of deterioration was also found in other studies. ${ }^{1320}$ Research has shown that frail patients at the time of hospital admission had poorer cognitive and physical functioning, with higher rates of delirium and cognitive impairment than those with cancer. ${ }^{21}$ Betterdeveloped care at nursing homes could prevent admissions for this group of patients. Obviously, different priorities in the expansion of care have an impact on the level of care. In Sweden, there has been a focus on dementia care in municipalities since the 1990s, which probably is the reason for the low number of dementia diagnoses in the Swedish hospitals in this study, $2.2 \%$ vs $26.3 \%$ in the Spanish hospitals.

There are other differences between the two countries: $34.4 \%$ of Swedish patients in palliative phases were hospitalised for acute treatment of congestive heart failure, vs only $9.2 \%$ in Spain. In comparison with other studies, heart failure is among the main diagnoses of non-cancer palliative patients. ${ }^{11} 1222$ Treatment for congestive heart failure is an example of what preferably should be taken care of in primary care or in the home care setting, given adequate resources. ${ }^{23}$ This has been recognised as a possibility in several Swedish county councils, where palliative care patients with severe symptoms of congestive heart failure are monitored and treated in home care settings by palliative care teams in co-operation with cardiologic consultants.
Two prominent symptoms, pain $(45 \%$ in Spain and $36 \%$ in Sweden) and infections (20\% and 26\%) are additional examples of healthcare problems that are usually manageable in the primary or home care setting, given optimal conditions. Although pain was a problem in up to $45 \%$ of patients, these values are still lower than those found in other studies. ${ }^{24} 25$ One explanation could be that our study design had focused on reasons for hospitalisation, not on all experienced symptoms. Although majority of earlier studies have focused on the assessment of single or multiple symptoms, symptoms can occur together and be related to each other as part of a cluster. Symptom cluster research can increase our understanding of symptomatology, improving symptom management in palliative care. ${ }^{92}$ In this regard, identification of symptom clusters in palliative care is an area of special interest $^{926}$ and research into this burden is required for this population.

Hospitalisation due to diagnostic procedures was very common for patients in this study, standing out in patients with cancer in Sweden. These results coincide with those obtained by Robinson et $a l^{12}$ in New Zealand, where the majority of patients had tests and investigations as the reason for admission to palliative care. Moreover, for patients with cancer, this type of care was a top priority, compared with non-cancer patients. One possible explanation for this finding may be the perceived need for patients with cancer to want more information about their disease status because of the uncertainty of its progression and prognosis. In other studies, ${ }^{27} 28$ patients with cancer highlight the need for information on the diagnosis and future condition, sometimes even more than information about physical symptoms. 
Social problems were more frequent reasons for hospitalisation in Spain than in Sweden. According to Fernández-López et al, ${ }^{29}$ a social problem is a complex criterion in palliative care in Spain and it is questionable whether social problems are best dealt with at an acute care hospital. However, social problems were not the main problems of the patients studied, nor were they recognised as a priority by the palliative patients in other studies. ${ }^{20}{ }^{27}$ At Swedish hospitals, a larger proportion of patients were hospitalised for well-defined care needs such as the need of palliative radiotherapy, pleuracenteses, diagnostic procedures and blood transfusions. Even if these seem to be relevant indications at first glance, these needs could be met in palliative home care, as palliative radiotherapy can be delivered on an ambulatory basis and measures such as pleuracenteses or blood transfusions are regularly provided in the home care environment in certain Swedish county councils, where medically advanced home care is offered around the clock, 7 days a week. Obviously, more palliative care training is needed in order to manage pain, infections and other symptoms outside the hospital. However, optimal organisations of palliative care are also important. In the catchment area for this study, the specialised palliative care teams only operated daytime, from Mondays to Fridays, which is not optimal. There are also different views on potentially avoidable admissions among hospitalised palliative patients. No doubt the development of specialised palliative care teams could help control the palliative patient at home. ${ }^{30}$ For example, Pellizzari et $a l^{31}$ found that integrating palliative home cancer care reduced both the hospital deaths and the hospital stay in the end of life.

\section{Early integrated palliative care}

Integration of palliative care into health systems might be a strategy to offer quality care at different levels, thereby reducing the need of acute hospital care. ${ }^{32}$ Early integrated palliative care at hospitals, has shown to improve the symptom burden among patients with advanced cancer. ${ }^{33}$ To provide palliative care, healthcare professionals need to identify patients as being in a palliative phase; however, there is still confusion regarding how to identify patients, especially those with non-cancer diagnoses. ${ }^{34}$ Possible explanations for the differences in the provision of palliative care for patients with cancer and those without could mainly be related to differences in the trajectory of the disease, fluctuating more in the case of diseases such as organ failure and dementia, which makes accurate prognosis difficult. Bostwick et $a l^{35}$ argue that non-cancer patients are less functional and may require more intensive care despite similar prognoses to patients with cancer.

Healthcare professionals' experiences in palliative care as well as their varying preconceptions of palliative care could also have an impact on how they identified patients as being in a palliative phase. ${ }^{36}$
Competence in palliative care is, therefore, needed to integrate palliative care early in the trajectory. ${ }^{37} \mathrm{~A}$ review of integrated palliative care in Spain shows that explanations of integrated palliative care exist, but with insufficient evidence of clinical impact. ${ }^{32}$ Though research has shown advantages of integrated palliative care, there is a paucity of how palliative care can optimally be implemented. ${ }^{37} 38$ One challenge is to use interprofessional communication to promote understanding and collaboration at different levels of care. The integration of palliative care at different levels of care could be a way of reducing the ambiguity of palliative care. We; therefore, believe that the integration of palliative care into the basic training of primary care teams, nursing homes and hospitals may be relevant in improving patient and family outcomes, providing emotional support and practical advice for patients and family members.

\section{Methodological considerations}

The assessment of patients as being in a palliative phase might differ between the countries; however, the definition was written on the questionnaire and also discussed with the persons responsible for the assessment. The symptoms and care needs were assessed by healthcare professionals and not by the patients themselves, which could have given a different spectrum of symptoms and care needs. However, the aim was to focus on symptoms and care needs related to hospitalisation, not all the experienced symptoms and care needs. Moreover, we only registered the occurrence of a certain symptom, for example, pain, not the intensity, which can be decisive when planning for an optimal level of care. The staff were only encouraged to address symptoms that were of clinical importance in the individual situation.

As we started our first registrations already in 2002 and have repeated them approximately every fifth year, we needed to create our own, study-specific questionnaire, as available questionnaires were lacking at that time. The detailed WHO's definition of palliative care from 2002 was printed on the back of the questionnaire and used as an aid. Today, there are specific instruments that can be used for the identification of patients that might have palliative care needs, for example, SPICT ${ }^{39} 40$ that originally was published in 2010 or NECPAL ${ }^{41}$ which was published in 2013. We have not used these instruments, which is a limitation. Our reason for not using them was that we wanted to be able to compare our results with our previous measurements from 2002, 2007 and 2012.

\section{CONCLUSIONS}

A significant proportion of patients with palliative care needs are cared for in acute care hospitals. Healthcare professionals need to be aware of the main reasons for hospitalisation of patients with palliative care needs to reduce unnecessary hospitalisations among this group, for whom alternative levels of care may be desirable. 
High frequencies of symptoms such as deterioration, pain and fatigue were found in both patients with cancer and non-cancer patients in both countries, although patients with cancer had higher frequencies of pain and non-cancer patients had higher frequencies of deterioration.

However, the similarities were higher, which indicates that the main focus in care should be on patient symptoms and care needs, rather than the patient diagnoses. Symptom cluster research can increase our understanding of symptomatology, improving symptom management. In this regard, further studies exploring symptom clusters in this population will be carried out.

Acknowledgements We would like to thank M Carmen Rodríguez-Torres and Teresa Sola Ortega, who collected the data in Spain. We would also like to thank Editage (www. editage.com) for English language editing.

Contributors The project leader (AS) developed the design along with PS; AS was also responsible for applying for research grants, monitoring the data, data collection and the administration of the questionnaire in Sweden, while FPGF and IMLM were responsible for this process in Spain. The analysis was conducted by AS with support from FPGF and DGS. Regular meetings involving the other authors were held throughout the analytical process. AS wrote the first draft of this manuscript, and FPGF, DGS, PS and IMLM contributed actively to the content and reviewed the text. All authors read and approved the final manuscript.

Funding This work was supported by Stiftelsen Ragnhild och Einar Lundströms Minne (LA2016-0407).

Competing interests None declared.

Patient consent for publication Not required.

Ethics approval The study was conducted in accordance with the Declaration of Helsinki of the World Medical Association[42]. In Spain, the study was ethically approved by the Jaen Biomedical Research Committee. In Sweden, ethical approval was obtained from the operation managers and department heads at the hospitals. Swedish law and praxis consider this study - which used no identifiable patient data - as part of normal clinical improvement procedures[43] and approval by an Ethics Committee was thus not necessary. Written information about the study was sent to the head nurses of the participating wards who selected a responsible nurse for the data collection. The nurses - often in cooperation with the physicians - assessed all inpatients, and those who were assessed as palliative were registered in the questionnaires. As no identifiable patient data was registered, informed consent was not required.

Provenance and peer review Not commissioned; externally peer reviewed.

Data availability statement Data are available on reasonable request.

Open access This is an open access article distributed in accordance with the Creative Commons Attribution Non Commercial (CC BY-NC 4.0) license, which permits others to distribute, remix, adapt, build upon this work noncommercially, and license their derivative works on different terms, provided the original work is properly cited, appropriate credit is given, any changes made indicated, and the use is noncommercial. See: http://creativecommons.org/licenses/by-nc/4. $0 /$.

\section{ORCID iDs}

Anna Sandgren http://orcid.org/0000-0002-3155-575X
Francisco P García-Fernández http://orcid.org/0000-00016038-3726

Daniel Gutiérrez Sánchez http://orcid.org/0000-0002-4773308X

Peter Strang http://orcid.org/0000-0001-8514-5433

Isabel M López-Medina http://orcid.org/0000-0002-3437-9229

\section{REFERENCES}

1 Murray MA, Fiset V, Young S, et al. Where the dying live: a systematic review of determinants of place of end-of-life cancer care. Oncol Nurs Forum 2009;36:69-77.

2 Robinson J, Gott M, Gardiner C, et al. The 'problematisation' of palliative care in hospital: an exploratory review of international palliative care policy in five countries. $B M C$ Palliat Care 2016;15:64.

3 Gomes B, Calanzani N, Gysels M, et al. Heterogeneity and changes in preferences for dying at home: a systematic review. BMC Palliat Care 2013;12:7.

4 Cabañero-Martínez MJ, Nolasco A, Melchor I, et al. Lugar de fallecimiento de las personas con enfermedades susceptibles de cuidados paliativos en LAS diferentes comunidades autónomas de España. Anales del Sistema sanitario de Navarra 2020.

5 Håkanson C, Öhlén J, Morin L, et al. A population-level study of place of death and associated factors in Sweden. Scand J Public Health 2015;43:744-51.

6 Vogl M, Schildmann E, Leidl R, et al. Redefining diagnosisrelated groups (DRGs) for palliative care - a cross-sectional study in two German centres. BMC Palliat Care 2018;17:58.

7 See D, Le B, Gorelik A, et al. Symptom burden in malignant and non-malignant disease on admission to a palliative care unit. BMJ Support Palliat Care 2019. doi:10.1136/ bmjspcare-2018-001560. [Epub ahead of print: $04 \mathrm{Feb}$ 2019].

8 Hui D, dos Santos R, Chisholm GB, et al. Symptom expression in the last seven days of life among cancer patients admitted to acute palliative care units. J Pain Symptom Manage 2015;50:488-94.

9 Stapleton SJ, Holden J, Epstein J, et al. Symptom clusters in patients with cancer in the hospice/palliative care setting. Support Care Cancer 2016;24:3863-71.

10 Tai S-Y, Lee C-Y, Wu C-Y, et al. Symptom severity of patients with advanced cancer in palliative care unit: longitudinal assessments of symptoms improvement. BMC Palliat Care 2016;15:32.

11 De Korte-Verhoef MC, Pasman HRW, Schweitzer BPM, et al. Reasons for hospitalisation at the end of life: differences between cancer and non-cancer patients. Support Care Cancer 2014;22:645-52.

12 Robinson J, Gott M, Frey R, et al. Circumstances of hospital admissions in palliative care: a cross-sectional survey of patients admitted to hospital with palliative care needs. Palliat Med 2018;32:1030-6.

13 Sandgren A, Strang P. Palliative care needs in hospitalized cancer patients: a 5-year follow-up study. Support Care Cancer 2018;26:181-6.

14 Moens K, Higginson IJ, Harding R, et al. Are there differences in the prevalence of palliative care-related problems in people living with advanced cancer and eight non-cancer conditions? A systematic review. J Pain Symptom Manage 2014;48:660-77.

15 World Health Organization. Definition of palliative care, 2002. Available: http://www.who.int/cancer/palliative/definition/en/ [Accessed 7 July 2019].

16 Sandgren A, Fridlund B, Nyberg P, et al. Symptoms, care needs and diagnosis in palliative cancer patients in acute care hospitals: a 5-year follow-up survey. Acta Oncol 2010;49:460-6.

17 Meffert C, Rücker G, Hatami I, et al. Identification of hospital patients in need of a palliative care--a predictive score. BMC Palliat Care 2016;15:21. 
18 Desmedt MS, de la Kethulle YL, Deveugele MI, et al. Palliative inpatients in general hospitals: a one day observational study in Belgium. BMC Palliat Care 2011;10:2.

19 Gott M, Frey R, Raphael D, et al. Palliative care need and management in the acute hospital setting: a census of one New Zealand Hospital. BMC Palliat Care 2013;12:15.

20 Gardiner C, Gott M, Ingleton C, et al. Extent of palliative care need in the acute hospital setting: a survey of two acute hospitals in the UK. Palliat Med 2013;27:76-83.

21 Huijberts S, Buurman BM, de Rooij SE. End-of-Life care during and after an acute hospitalization in older patients with cancer, end-stage organ failure, or frailty: a sub-analysis of a prospective cohort study. Palliat Med 2016;30:75-82.

22 Van Lancker A, Van Hecke A, Verhaeghe S, et al. A comparison of symptoms in older hospitalised cancer and non-cancer patients in need of palliative care: a secondary analysis of two cross-sectional studies. BMC Geriatr 2018;18:40.

23 Näsström L, Jaarsma T, Idvall E, et al. Patient participation in patients with heart failure receiving structured home care - a prospective longitudinal study. BMC Health Serv Res 2014;14:633.

24 Falk H, Henoch I, Ozanne A, et al. Differences in symptom distress based on gender and palliative care designation among hospitalized patients. J Nurs Scholarsh 2016;48:569-76.

25 van den Beuken-van Everdingen MHJ, Hochstenbach LMJ, Joosten EAJ, et al. Update on prevalence of pain in patients with cancer: systematic review and meta-analysis. J Pain Symptom Manage 2016;51:1070-90.

26 Stiel S, Matthies DMK, Seuß D, et al. Symptoms and problem clusters in cancer and non-cancer patients in specialized palliative care - is there a difference? J Pain Symptom Manage 2014;48:26-35.

27 Ndiok A, Ncama B. Assessment of palliative care needs of patients/families living with cancer in a developing country. Scand J Caring Sci 2018;32:1215-26.

28 Heins M, Hofstede J, Rijken M, et al. Palliative care for patients with cancer: do patients receive the care they consider important? A survey study. BMC Palliat Care 2018;17:61.

29 Fernández-López A, Sanz-Amores R, Cía-Ramos R, et al. Criterios y niveles de complejidad en Cuidados Paliativos. Medicina paliativa 2008;15:287-92.

30 Schelin ME, Sallerfors B, Rasmussen BH, et al. Quality of care for the dying across different levels of palliative care development: a population-based cohort study. Palliat Med 2018;32:1596-604.
31 Pellizzari M, Hui D, Pinato E, et al. Impact of intensity and timing of integrated home palliative cancer care on end-oflife hospitalization in Northern Italy. Support Care Cancer 2017;25:1201-7.

32 Garralda E, Hasselaar J, Carrasco JM, et al. Integrated palliative care in the Spanish context: a systematic review of the literature. BMC Palliat Care 2016;15:49.

33 Bandieri E, Banchelli F, Artioli F, et al. Early versus delayed palliative/supportive care in advanced cancer: an observational study. BMJ Support Palliat Care 2020;10:e32.

34 Van Mechelen W, Aertgeerts B, De Ceulaer K, et al. Defining the palliative care patient: a systematic review. Palliat Med 2013;27:197-208.

35 Bostwick D, Wolf S, Samsa G, et al. Comparing the palliative care needs of those with cancer to those with common non-cancer serious illness. J Pain Symptom Manage 2017;53:1079-84.

36 Wallerstedt B, Benzein E, Schildmeijer K, et al. What is palliative care? Perceptions of healthcare professionals. Scand J Caring Sci 2019;33:77-84.

37 Aldridge MD, Hasselaar J, Garralda E, et al. Education, implementation, and policy barriers to greater integration of palliative care: a literature review. Palliat Med 2016;30:224-39.

38 Kaasa S, Loge JH, Aapro M, et al. Integration of oncology and palliative care: a Lancet oncology Commission. Lancet Oncol 2018;19:e588-653.

39 Highet G, Crawford D, Murray SA, et al. Development and evaluation of the supportive and palliative care indicators tool (SPICT): a mixed-methods study. BMJ Support Palliat Care 2014;4:285-90.

40 Boyd K, Murray SA. Recognising and managing key transitions in end of life care. BMJ 2010;341:c4863.

41 Gómez-Batiste X, Martínez-Muñoz M, Blay C, et al. Identifying patients with chronic conditions in need of palliative care in the general population: development of the NECPAL tool and preliminary prevalence rates in Catalonia. BMJ Support Palliat Care 2013;3:300-8.

42 World Medical Association. World Medical association Declaration of Helsinki, 2008. Available: http://www.wma.net/ e/policy/b3.htm [Accessed 7 Jul 2019].

43 Etikprövningsmyndigheten. Available: https://etikprovning smyndigheten.se [Accessed 7 Jul 2019]. 